\title{
Proteomic analysis of oxymatrine-induced changes in lung fibroblasts
}

\author{
Xiao-Hong Chen ${ }^{1 *}$, Ren-Shan Sun ${ }^{3}$, Yi-Ran $\mathrm{Li}^{1}$, Dong-Jiang Liao ${ }^{2}, \mathrm{Zi}-\mathrm{Yao}_{\mathrm{Mo}}{ }^{2}$, Zi-Feng Yang ${ }^{2}$, \\ Jian-Ming $\mathrm{Hu}^{2}$, Wen-Da Guan ${ }^{2}$ and Nan-Shan Zhong ${ }^{2}$ \\ ${ }^{1}$ Department of Pharmacology, College of Pharmacy, Third Military Medical University, Chongqing 400038, China. \\ ${ }^{2}$ State Key Laboratory of Respiratory Disease, The first affiliated hospital of Guangzhou Medical College, Guangzhou \\ Medical College, Guangzhou 510120, China. \\ ${ }^{3}$ Department of Dermatology, Daping Hospital, Third Military Medical University, Chongqing 400042, China.
}

Accepted 4 October, 2012

\begin{abstract}
Oxymatrine, one kind of alkaloids extracted from Sophora flavescens Ait, has been demonstrated to attenuate bleomycin-induced lung fibrosis. The mechanisms of this action are poorly known. This study aimed to use proteomics to provide new insights into the mechanisms of the pharmacological effects. Proteins from murine lung fibroblasts exposed to oxymatrine were separated by two-dimensional electrophoresis. Differentially expressed proteins were identified using mass spectrometry. A twodimensional cell migration assay was used to study the effects of oxymatrine on fibroblast migration activity. Among these detectable protein spots on the 2-DE gel 9 protein, spots were significantly altered in oxymatrine treated cells. 5 proteins were successfully identified. All were down-regulated by oxymatrine. Mass spectrometer analysis indicated that one of these proteins is a metabolic enzyme, while others are related to cytoskeleton or involved in cellular transcription and translation. The attenuated expressions of mRNA and protein of the cytoskeleton-related protein, HSP27, were confirmed by Western blotting and RT-PCR analysis. Besides these, the migration activity of fibroblast was reduced by oxymatrine. It is suggested that regulation of HSP27 expression by oxymatrine is associated with its inhibitory effects on motility of lung fibroblasts, which contributes to the protective action of this drug against lung fibrosis.
\end{abstract}

Key words: Oxymatrine, fibroblasts, proteomics, heat shock protein 27, motility

\section{INTRODUCTION}

Pulmonary fibrosis is characterized by an absolute increase of collagen-rich extracellular matrix. The accumulation of extracellular matrix, damage of alveolar wall and loss of functional capillary units can lead to respiratory failure within a few years after diagnostic confirmation. Specific treatments for fibrotic lung diseases are not yet available. Therefore, novel therapeutic agents with improved efficacy are needed (Datta et al., 2011; Gross and Hunninghake, 2001).

Up to now, our understanding of the pathogenesis of this condition is incomplete. However, it is likely that

${ }^{*}$ Corresponding author. E-mail: pharsunr@126.com. Tel: 86-2368752266. Fax: 86-23-68752266. multiple abnormalities in a myriad of biological pathways affect inflammation and wound repair, including matrix regulation, epithelial reconstitution, the coagulation cascade, neovascularization and antioxidant pathways. Current research results indicated that fibroblast activetion lead to progressive fibrosis. Therefore, regulation of fibroblasts should be an important therapeutic strategy (Datta et al., 2011).

Oxymatrine (OM) is an alkaloid extracted from Sophora flavescens Ait (a traditional Chinese medicine belonging to the pulse family) (Wu et al., 2006). In China, OM as a clinical drug has been used to treat viral hepatitis, cardiac arrhythmia and skin inflammations (Dong et al., 2002; Liu et al., 1994, 2003). It has been proven to be an effective inhibitor of tissues fibrosis, including hepatic fibrosis, myocardical fibrosis, pulmonary fibrosis (Shi and Li, 2005; 
Shen et al., 2011; Liu et al., 2012). The protective effects of OM on pulmonary fibrosis are related with the inhibition of inducible nitric oxide synthase expression and the TGF- $\beta$ /Smad signaling pathway (Shen et al., 2011; Liu et al., 2012). However, the mechanisms of the effects of OM are largely unknown, especially the effects of $\mathrm{OM}$ on lung fibroblasts.

Proteomic methodologies, including two-dimensional electrophoresis (2-DE) and mass spectrometry (MS), provide a general route to analyze the global protein expression of cells at different status. Proteomic analysis has been successfully applied to investigate the molecular effects of drugs and to obtain information regarding their mode of action (Elrick et al., 2006). In this paper, fibroblasts derived from lung of mice were treated with $\mathrm{OM}$, and the protein profiling of fibroblasts was analyzed and compared.

The functional implications of the differentially expressed proteins, which may play important roles in mediating OM's effects on fibroblasts, were discussed. To confirm the expression changes of proteins by proteomics analysis, Western blot and Reverse transcription polymerase chain reaction (RT-PCR) were performed. We believe that such global proteins expression study could allow improved understanding of the mechanisms of OM's protective effects on mice with pulmonary fibrosis.

\section{MATERIALS AND METHODS}

\section{Reagents}

OM was purchased from Yixin pharmaceuticals (Zhejiang, China). It was dissolved in distilled Dulbecco's modified Eagle's medium (DMEM) and stored at $4^{\circ} \mathrm{C}$. IPG strip (pH 3 to 10), pharmalyte ( $\mathrm{pH} 3$ to 10), high-performance liquid chromatography (HPLC)-grade acetonitrile (ACN) were purchased from Bio-Rad (Hercules, CA, USA). a-Cyano-4-hydroxycinnamic acid (CHCA), ammonium persulphate (APS), sodium dodecyl sulphate (SDS), glycine, glycerol, ultra pure urea, acrylamide, dithiothreitol (DTT), 3[3(cholamidopropyl) dimethylammonio]-1-propane-sulphonate (CHAPS), ultra pure Coomassie R-250 were purchased from Sigma-Aldrich Corp. (St. Louis MO, USA). Rabbit polyclonal IgG antibody to rodent heat shock protein 27 (HSP27) was provided by Cell Signaling Technology, Inc. (Danvers, USA). Chemiluminescence Western blotting detection reagent (ECL Plus) was purchased from Pierce Biotechnology (Rockford, USA). The Prime Script $^{\mathrm{TM}}$ 1st Strand cDNA Synthesis Kit and PCR Amplification Kit were purchased from TaKaRa Biotechnology (Otsu, Japan). All other chemicals were of analytical grade.

\section{Cell culture}

Lung fibroblasts from health adult mice were isolated according to the method by Phan et al. (1985) as before. The cells were cultured in DMEM supplemented with $10 \%$ fetal bovine serum (FBS) maintained at $37^{\circ} \mathrm{C}$ in a humidified incubator in an atmosphere of $5 \% \mathrm{CO}_{2}$ in air. After reaching subconfluence, cells were cultured in serum-free DMEM for $24 \mathrm{~h}$, then challenged with or without OM 1.0 $\mathrm{mg} / \mathrm{mL}$ over 72 h. All procedures were approved by Ethics Committee of The Guangzhou Medical College.

\section{Two-dimensional gel electrophoresis}

OM treated or the control cells were collected and lysed in lysis buffer $(7 \mathrm{mmol} / \mathrm{mL}$ urea, $2 \mathrm{mmol} / \mathrm{mL}$ thiourea, 4\% CHAPS, 65 $\mu \mathrm{mol} / \mathrm{mL}$ DTT, $015 \mu \mathrm{mol} / \mathrm{mL}$ EDTA, $2 \mu \mathrm{mol} / \mathrm{mL}$ PMSF), sonicated in six cycles of $15 \mathrm{~s}$. After centrifugation at $12000 \times \mathrm{g}$ for $1 \mathrm{~h}$ at $4^{\circ} \mathrm{C}$, the protein concentration was estimated with the method of Bradford (Bio-Rad, Richmond, CA, USA) (Tsai et al., 2008; RuizRomero et al., 2009). The first dimension (IEF) was performed on a Protean IEF Cell apparatus (Bio-Rad) as follows: $800 \mu \mathrm{g}$ protein samples were applied to an IPG strip, pH 3 to 10 (Bio-Rad). The strips were soaked in the sample solution for $1 \mathrm{~h}$ to allow uptake of the proteins. The strip was then actively rehydrated in a Protean IEF cell (Bio-Rad) for $16 \mathrm{~h}$ at $50 \mathrm{~V}$. The isoelectric focusing was at $300 \mathrm{~V}$ for $2 \mathrm{~h}$ linearly, $500 \mathrm{~V}$ for $2 \mathrm{~h}$ linearly, $1000 \mathrm{~V}$ for $2 \mathrm{~h}$ linearly, $8000 \mathrm{~V}$ for $8 \mathrm{~h}$ linearly, and $8000 \mathrm{~V}$ for $10 \mathrm{~h}$ rapidly. All the processes above were carried out at $22^{\circ} \mathrm{C}$. After equilibration, SDSpolyacrylamide gel electrophoresis (PAGE) was performed on an Protean II XL system (Bio-Rad). The gels were then stained overnight using R-250 Coomassie blue and destained in $1 \%(\mathrm{v} / \mathrm{v})$ acetic acid solution on a gently continuous rocker.

\section{Image analysis}

The two-dimensional gels were scanned using an Image Scanner (GE HealthCare). The peptide spots were analyzed with ImageMaster 2D Elite 5.0 software (Amersham Biosciences). All well-separated and clearly focused spots that were 2-fold differentially expressed between the control and OM treated fibroblasts were classified as up- or down- regulated spots, and then selected for mass spectrometric analysis (Tsai et al., 2008; Ruiz-Romero et al., 2009).

\section{Mass spectrometry analysis and protein identification}

Selected protein spots were excised from the 2-DE gel and destained and digested in-gel with trypsin, as previously described (D'Hertog et al., 2007). Then, the collected samples were analyzed with a MALDI-TOF/TOF (ABI 4700 Proteomics Analyzer, Applied Biosystems). For protein identification, the obtained mass information was searched against the National Center for Biotechnology Information (NCBI) protein databases using the MASCOT search engine (www.matrixscience.com) (Qian et al., 2008).

\section{Western blotting}

Cells were scraped off the plates after treated with $0,1.0,0.5,0.25$ or $0.125 \mathrm{mg} / \mathrm{mL}$ of $\mathrm{OM}$ and incubated for $30 \mathrm{~min}$ in lysis buffer. After centrifugation, a portion of supernatant was used for protein concentration determination using the Bio-Rad protein assay. Equal amounts of protein $(20 \mu \mathrm{g})$ were loaded onto a $10 \%$ polyacrylamide gel, electrophoresed and transferred to polyvi polyvinylidene difluoride (PVDF) membrane. The blots were blocked for $1 \mathrm{~h}$ with $5 \%$ non-fat milk reagent dissolved in TBST $(1 \times$ Tris-buffered saline with $0.05 \%$ Tween-20). Membranes were incubated with an antiHSP27 monoclonal antibody $(1: 1000)$. Anti-GAPDH polyclonal antibody was used as an internal standard. Detection was done using an enhanced chemiluminescence (ECL) system.

\section{Reverse-transcription polymerase chain reaction}

The mRNA expressions of HSP27 were determined by reversetranscription polymerase chain reaction (RT-PCR) analyses. After 
being treated with or without OM, cells were harvested and total RNA was extracted using standard Trizol RNA isolation method. Reverse transcription of $5 \mu \mathrm{g}$ RNA was carried out according to the instruction of TaKaRa RT-PCR kit (TaKaRa Biotechnology, Otsu, Japan). The PCR amplification was conducted by a Biometra TGradient thermal cycler (Biometra, Tampa, FL, USA) according to the following protocol: solutions were denatured at $94^{\circ} \mathrm{C}$ for $30 \mathrm{~s}$, annealed at $58^{\circ} \mathrm{C}$ for $30 \mathrm{~s}$, extended at $72^{\circ} \mathrm{C}$ for $60 \mathrm{~s}$, and amplified by 35 cycles. The primers used were listed in Table 1. PCR products were separated by electrophoresis on $2.0 \%$ agarose gels and stained with ethidium bromide. The density of bands was analyzed using a Bio-Rad GS-700 densitometer (Foster City, CA, USA). Ratios of target genes to house-keeping gene glyceraldehyde-3-phosphate dehydrogenase (GAPDH) were calculated.

\section{Two-dimensional cell migration assay}

A two-dimensional cell migration assay using a wound-healing model was performed as previously described (Santos et al., 1997). Briefly, confluent cells seeded on 24-well culture plates were treated with $\mathrm{OM}$ at dose of $0,1.0,0.5,0.25$ or $0.125 \mathrm{mg} / \mathrm{mL}$ for 24 h. The monolayer cells were then scraped with a sterile $200 \mu \mathrm{l}$ pipette tip to create a double-sided wound. After being washed with PBS, media were replaced with fresh media containing DMEM supplemented with $0,1.0,0.5,0.25$ or $0.125 \mathrm{mg} / \mathrm{mL}$ of OM. After this, time-lapse images were captured using an inverted phase contrast microscope at $100 \times$ magnification for $24 \mathrm{~h}$. Cell migration was evaluated by calculating the average cell migration velocity using the following formula:

The average cell migration velocity $=$ migration distance/migration time

\section{Cell proliferation}

MTT assay was used to measure cell proliferation of OM on fibroblasts. Cells were seeded on 96 -well plates $\left(1 \times 10^{4}\right.$ cells/well). After fibroblasts were treated with different concentrations of OM for $48 \mathrm{~h}$, media were carefully aspirated. $200 \mu \mathrm{l}$ of $0.5 \mathrm{mg} / \mathrm{ml} \mathrm{3-}(4,5-$ dimethylthiazol-2-yl)-2,5-diphenyltetrazolium bromide (MTT) was added into wells and incubated for $4 \mathrm{~h}$. Then, $150 \mu \mathrm{l}$ of dimethyl sulphoxide was added and the absorbance at $490 \mathrm{~nm}$ was determined. Percentage of cell proliferation was calculated as (OD of treated sample/OD of untreated control) $\times 100$.

\section{Statistical analysis}

Data were expressed as mean \pm standard deviation. Data analysis was performed using SPSS 12.0 software package. After homogeneity of variances was confirmed by Levene's test $(P>$ 0.05), homogeneous data were analyzed with the least significant difference (LSD) test for multiple comparisons following one-way ANOVA. To determine inter-group differences, heterogeneous data were analyzed with Dunnett T3 test. A value of $P<0.05$ was considered significant.

\section{RESULTS}

\section{Two-dimensional protein maps of the fibroblasts}

The protein expression profile of the control reagent or
OM treated fibroblasts was examined by 2-DE. The experiments were repeated at least three times with reproducible results. Representative high resolution $2-\mathrm{DE}$ was able to resolve hundreds of proteins as shown in Figure 1. A total of 1136 protein spots were detected in the control fibroblasts, while 1020 spots were detected in OM treated fibroblasts when analyzed with ImageMaster 5.0 .

\section{Changes in protein expression}

Furthermore, we used ImageMaster 5.0 to identify the quantitatively differentially expressed proteins on the 2DE gel between the control and OM treated cells. Among these detectable protein spots, we were able to pinpoint a total of 9 spots expressed differentially in response to $\mathrm{OM}$ treatment (-fold changes in protein expression $\geq 3$ ). Of these protein spots, 2 were of higher intensities, 7 were of lower intensities (Figure 2). Using MALDI-TOF/TOF analysis and NCBInr protein databases, 5 proteins were successfully recognized. They were heat shock protein 27 (HSP27), myosin regulatory light chain 1 (MRLC1), eukaryotictranslation initiation factor 3 (EIF3), mitochondrial phosphoenolpyruvate carboxykinase 2(PEPCK), mus musculus transcription factor $\mathrm{S}$--II--related proteins (TFSII). All expressions were markedly decreased in OM exposed cells. The identification of these proteins along with their accession numbers, MW, PI and protein score was shown in Table 2.

\section{Changes of HSP27 induced by OM}

To verify the effects of OM on HSP27 expression in primary lung fibroblasts, the RT-PCR and western-blot studies were conducted. By RT-PCR analysis, it was found that the expression of HSP27 mRNA of fibroblasts derived from lung of mice was significantly lower than that of control cells $(P<0.01)$ (Figure 3$)$. In addition, western-blot results presented in Figure 4 showed that OM can also lower the protein expression of HSP27 at the dose from 0.25 to $1.0 \mathrm{mg} / \mathrm{mL}$. The feature was the drug concentration-effect dependence. There is a significant difference compared with the control group $(\mathrm{P}<$ 0.05). The result was in accordance with that of twodimensional gel electrophoresis.

\section{Effects of OM on migration of fibroblasts}

HSP27 has been proven to behave as an actin-capping protein to regulate many cell activities, including motility, proliferation, contraction, and so on. In this study, we studied the effect of $\mathrm{OM}$ on fibroblast migration using an in vitro scrape-injury model. As shown in Figure 5, the average cell migration velocity was significantly reduced 
Table 1. Primer pairs for reverse-transcription polymerase chain reaction in the study.

\begin{tabular}{lllc}
\hline & Forward & Reverse & Product (base pair) \\
\hline Hsp27 & CAAGGAAGGCGTGGTGGA & GCCTCGAAAGTAACCGGAATG & $\mathbf{2 2 2}$ \\
GAPDH & ATGACCTTGCCCACAGCC & CCCATCACCATCTTCCAG & $\mathbf{4 4 5}$ \\
\hline
\end{tabular}

Table 2. Identified proteins by MALDI-TOF/TOF.

\begin{tabular}{clcccc}
\hline Spot No. & protein name & Accession No. & M.W. Da & PI & Score \\
\hline 1 & Heat shock protein 27 & IPI00468068 & 21947.2 & 2.45 & 364 \\
2 & Myosin light chain & IPI00109044 & 19882.5 & 4.67 & 431 \\
3 & Eukaryotictranslation initiation factor 3 & IPI00115580 & 42489.9 & 5.5 & 331 \\
4 & Mitochondrial phosphoenolpyruvate carboxykinase 2 & IPI00223060 & 73371 & 7.88 & 312 \\
5 & Mus musculus transcription factor S-II-related proteins & IPI00323639 & 9342 & 11.35 & 50 \\
\hline
\end{tabular}

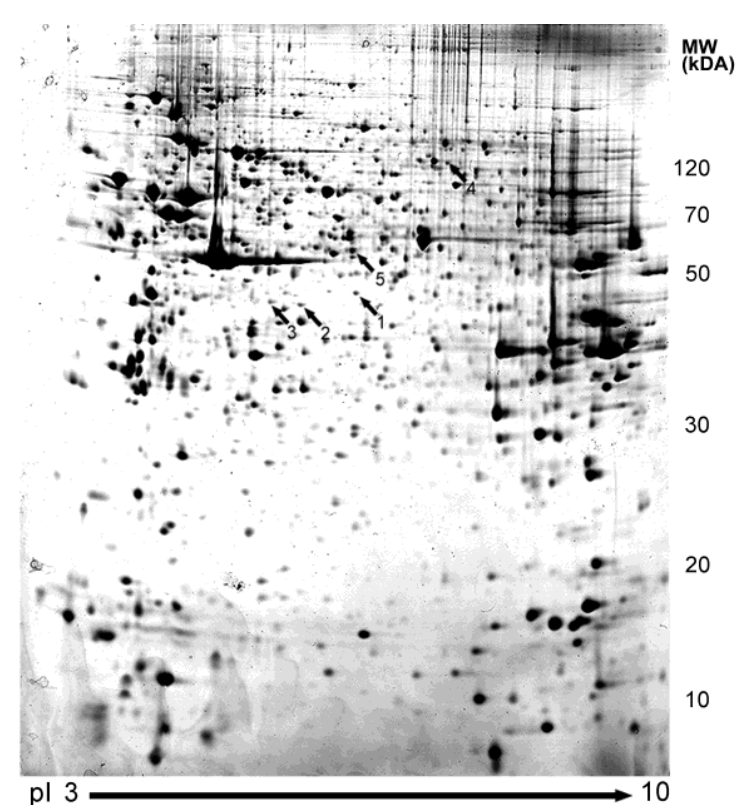

Control

A

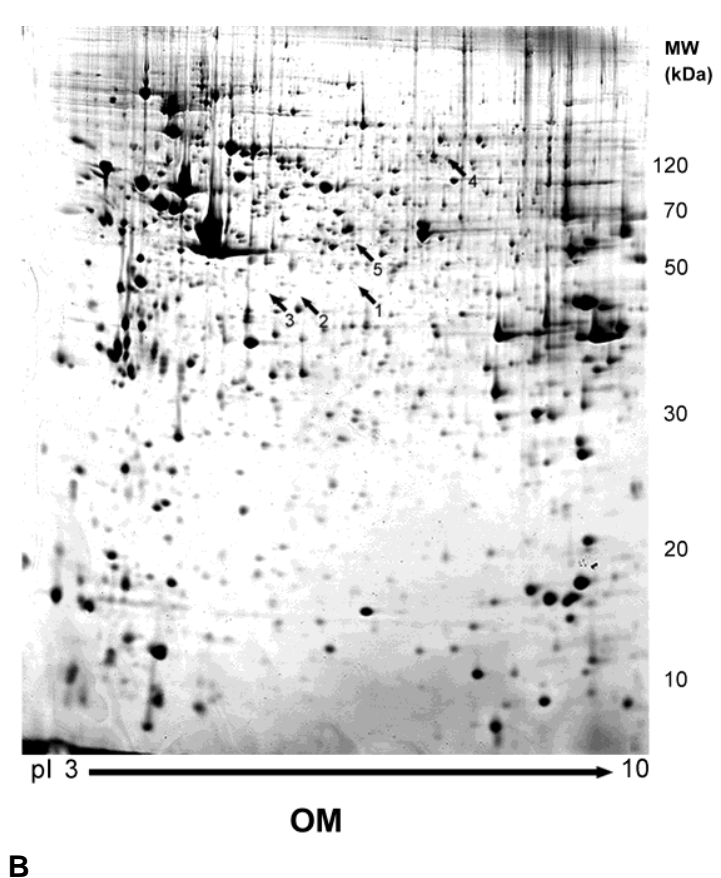

Figure 1. Differential expression of proteins from mouse lung fibroblasts visualized by two-dimensional polyacrylamide gel electrophoresis (2-DE) gel. Protein extracted from the lung fibroblasts of mouse untreated (a) or treated (b) with $\mathrm{OM}$ was separated by 2-DE (first dimension, $\mathrm{pH} 3$ to 10, non-linear gradient of IPG strips; second dimension, $12 \%$ SDS-PAGE) and visualized by coomassie blue staining. The orientation of the IEF strips is indicated at the top of gels. Molecular mass standards are shown on the right of the 2-DE gel.

by $\mathrm{OM}$ with a dose dependent manner $(\mathrm{P}<0.05)$. The results indicated that $\mathrm{OM}$ suppresses fibroblast migration, possibly through HSP27.

\section{Effects of OM on proliferation of fibroblasts}

Fibroblast proliferation was evaluated using MTT analysis. Lung fibroblasts from mice were cultured in the presence of OM. As shown in Figure 6, no statistical differences were obtained between the control group and the OM-treated groups at doses of $1.0,0.5,0.25$ or 0.125 $\mathrm{mg} / \mathrm{mL}$ at $48 \mathrm{~h}$.

\section{DISCUSSION}

Two-dimensional electrophoresis offers an efficient tool to 

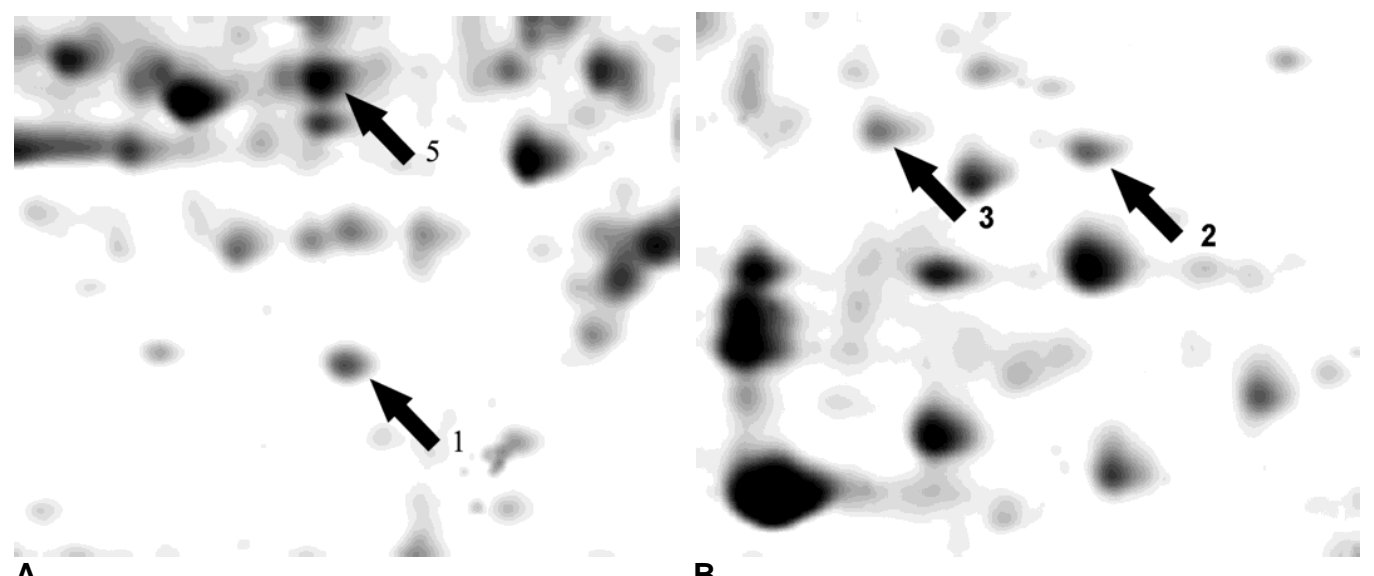

A

B
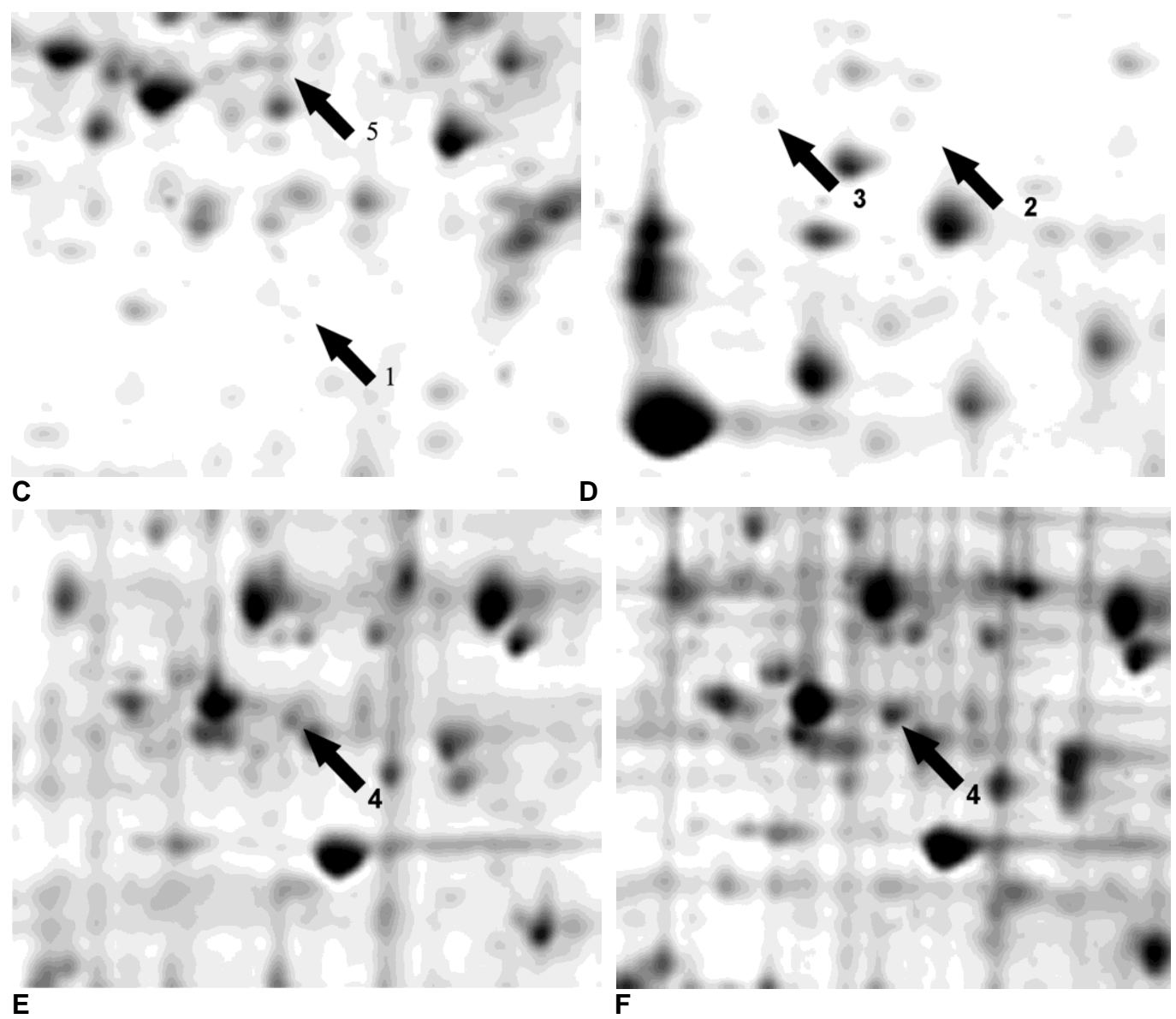

Figure 2. Enlargement of selected portions of the two-dimensional electrophoresis (2-DE) gel images. shown of control (A, B and C) and OM treated fibroblasts (D, E and F). The locations of spots that significantly altered after oxymatrione use were indicated by arrows.

screen for abundant protein changes in cells in different states. In the present study, a full characterization of the fibroblast proteome and the global changes in protein expression caused by $\mathrm{OM}$ at the dose of $1 \mathrm{mg} / \mathrm{mL}$ were demonstrated with 2-DE and MOLDT-TOF/TOF MS analysis.

Our results showed that a total of 9 spots differentially expressed in fibroblasts treated with OM compared with the control cells. 5 proteins were successfully identified. All were down-regulated in cells exposed to OM. Mass spectrometer analysis indicated that one of these proteins is a metabolic enzyme, while others are related to cytoskeleton or involved in cellular transcription and translation. 

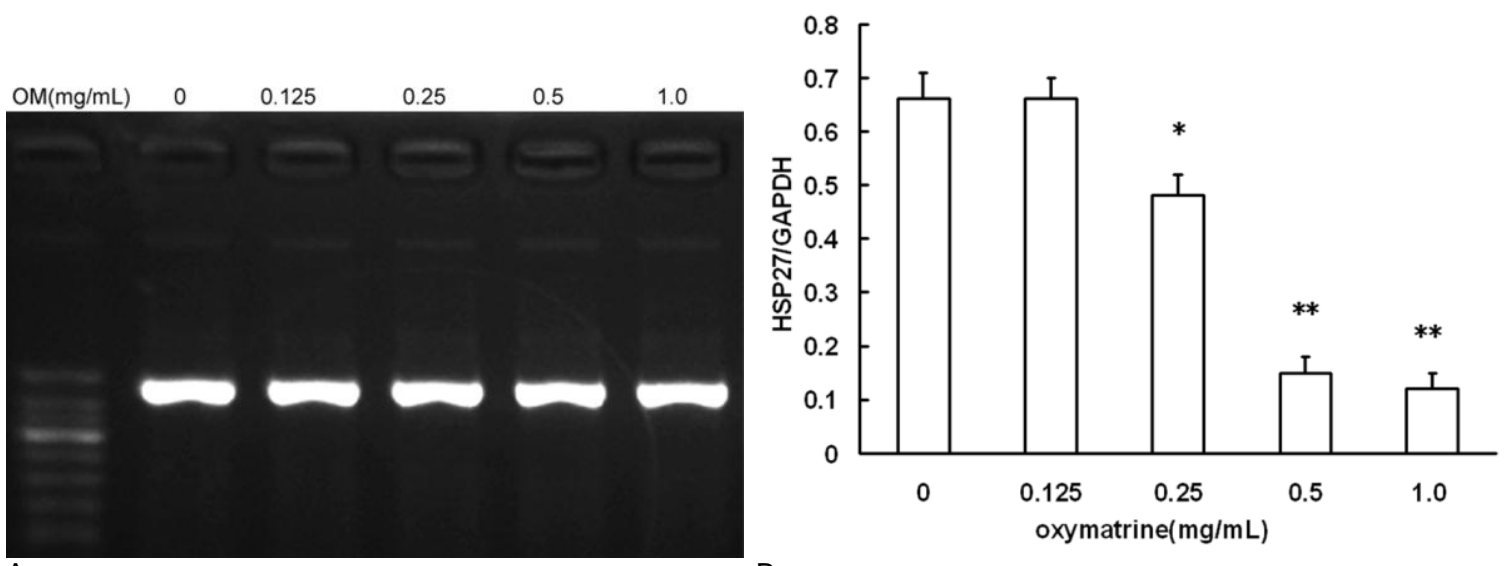

$B$

Figure 3. Effects of oxymatrine treatment on the mRNA levels of heat shock protein 27 (HSP27) in lung fibroblasts. The mRNA expression was determined by semiquantitative reverse-transcription PCR. (A) Expression of HSP27 mRNA in cultured lung fibroblasts detected $48 \mathrm{~h}$ after oxymatrine administration, (B) relative ratio of densitometry of HSP27 to GAPDH ( $n=3$ in each group). Data are mean \pm S.E.M. ${ }^{* *} p<0.01,{ }^{* \star *} p<0.001$, compared with the control group.

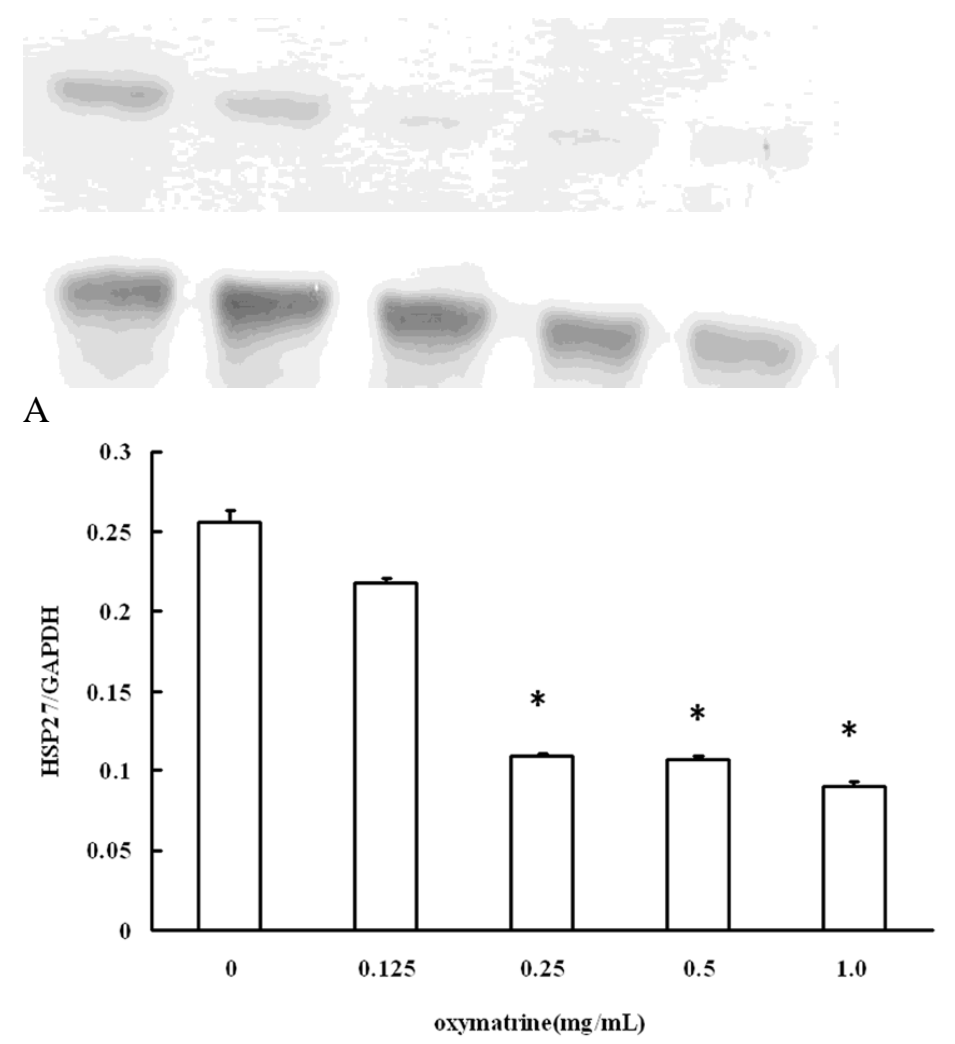

B

Figure 4. The effects of oxymatrine on the protein levels of heat shock protein 27 (HSP27) in lung fibroblasts. The effects of oxymatrine on the protein levels of heat shock protein 27 (HSP27) were detected by Western blot analysis. (A) Expression of HSP27 protein in lung fibroblasts incubated with or without oxymatrine for $48 \mathrm{~h}$, (B) relative ratio of densitometry of HSP27 to GAPDH ( $n=3$ in each group). Data are mean \pm S.E.M. ${ }^{*} p<0.05,{ }^{* *} p<0.01$, compared with the control group. 


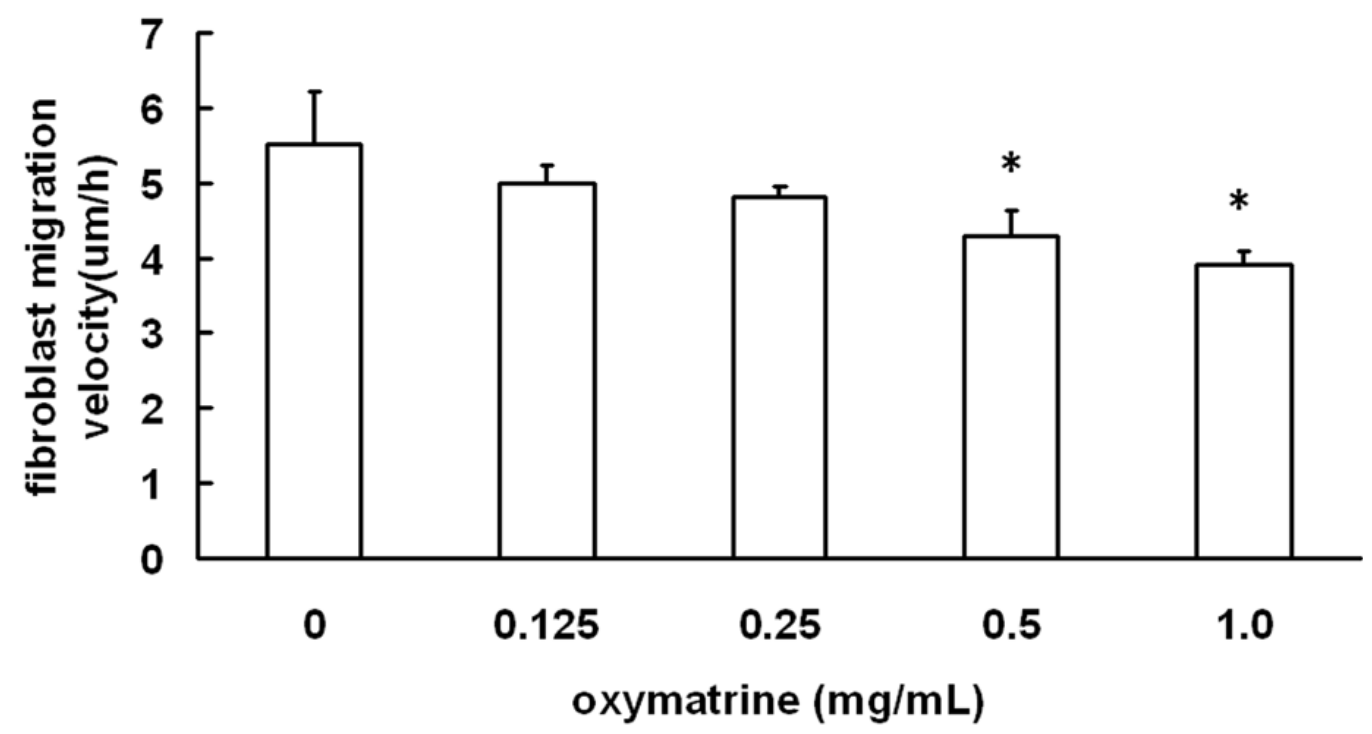

Figure 5. Effect of oxymatrine on the migration of lung fibroblasts in a two-dimensional cell migration assay. Confluent fibroblasts were damaged with a pipette tip. After wound healing for $24 \mathrm{~h}$ in the present or not present of oxymatrine, the cell migration velocity was computed ( $n=3$ in each group). Data are mean \pm S.E.M. ${ }^{*} P<0.05$ compared with the control group.

Myosin regulatory light chain 1 (MRLC1) and HSP27, both found to be reduced by OM, are cytoskeletonrelated proteins and can influence cellular processes, such as proliferation, contraction, cell adhesion, cytokinesis, cell motility, and migration. MRLC1 is a regulatory protein and belongs to the myosin light chains family (Swant et al., 2005) while HSP27 is a member of the stress-inducible small heat shock protein family, heat shock proteins (HSPs). It behaves as an actin-capping protein, interfering with its polymerization by modulating RhoA-ROCKII pathway, then regulating phosphorylation of MRLC (Hiragami et al., 2009). In this study, changes of HSP27 induced by OM have been confirmed by RT-PCR and western-blot analysis at mRNA and protein levels, the latter was in accordance with the result of twodimensional gel electrophoresis.

Recently, HSP27 was found expressed at very high levels in fibroblast foci, a relevant morphologic marker of idiopathic pulmonary fibrosis/usual interstitial pneumonia (IPF/UIP). Usually, fibroblast foci are recognized as sites where fibrotic responses are initiated and/or perpetuated in this severe disease. Thus, HSP27 was considered partly responsible for the abnormal proliferation and migration of mesenchymal fibroblasts and has a major role in the remodeling process characterizing IPF/UIP (Chilosi et al., 2006). In this present study, MTT assay indicated that proliferation of fibroblasts exposured to OM for $48 \mathrm{~h}$ showed no significant changes compared with that of the control group. However, the results of cell motility showed that the average cell migration velocity was significantly reduced by $\mathrm{OM}$ at $48 \mathrm{~h}$, with a dose dependent manner $(P<0.05)$. Based on those observations, we suggest the mechanisms by which OM attenuates pulmonary fibrosis involve inhibition of fibroblast migration, and it might be partly related to regulation of HSP27 expression.

Phosphoenolpyruvate carboxykinase (PEPCK) is a rate controlling enzyme in gluconeogenesis which catalyzes the synthesis of phosphoenolpyruvate from oxaloacetate. Recent studies have suggested that PEPCK plays important role in the maintenance of blood glucose concentration (Huang et al., 2010; Kim et al., 2009). In this paper, PEPCK decreased in cells exposed to OM, which indicates that OM may disrupt glucose homeostasis by inhibiting gluconeogenesis. The results suggested that the inhibition effect of OM on PEPCK at least partly contributed to its attenuation of proliferation and mobility of fibroblast. Moreover, transcription factor S-II (TFSII) and eukaryotic translation initiation factor 3 (EIF3) were found down regulated in the OM treated cells. TFSII was a transcription elongation factor which directly binds the transcription motor, RNA Polymerasell and allows it to be read by various transcription arrest sites.

Recent studies revealed that knockdown of TFSII reduced cancer cell proliferation and induced apoptosis in cancer cells (Hubbard et al., 2008; Kanai et al., 1991). The results of the study indicated that OM may interfere with the proliferation of fibroblast by the transcription machinery. EIF3 is a large multiprotein complex. Its major effect on initiation complex formation of eukaryotic translation is to loosen the interactions between the ribosomal subunits, making the small subunit available for fMet-tRNA binding. Recently, some evidences 


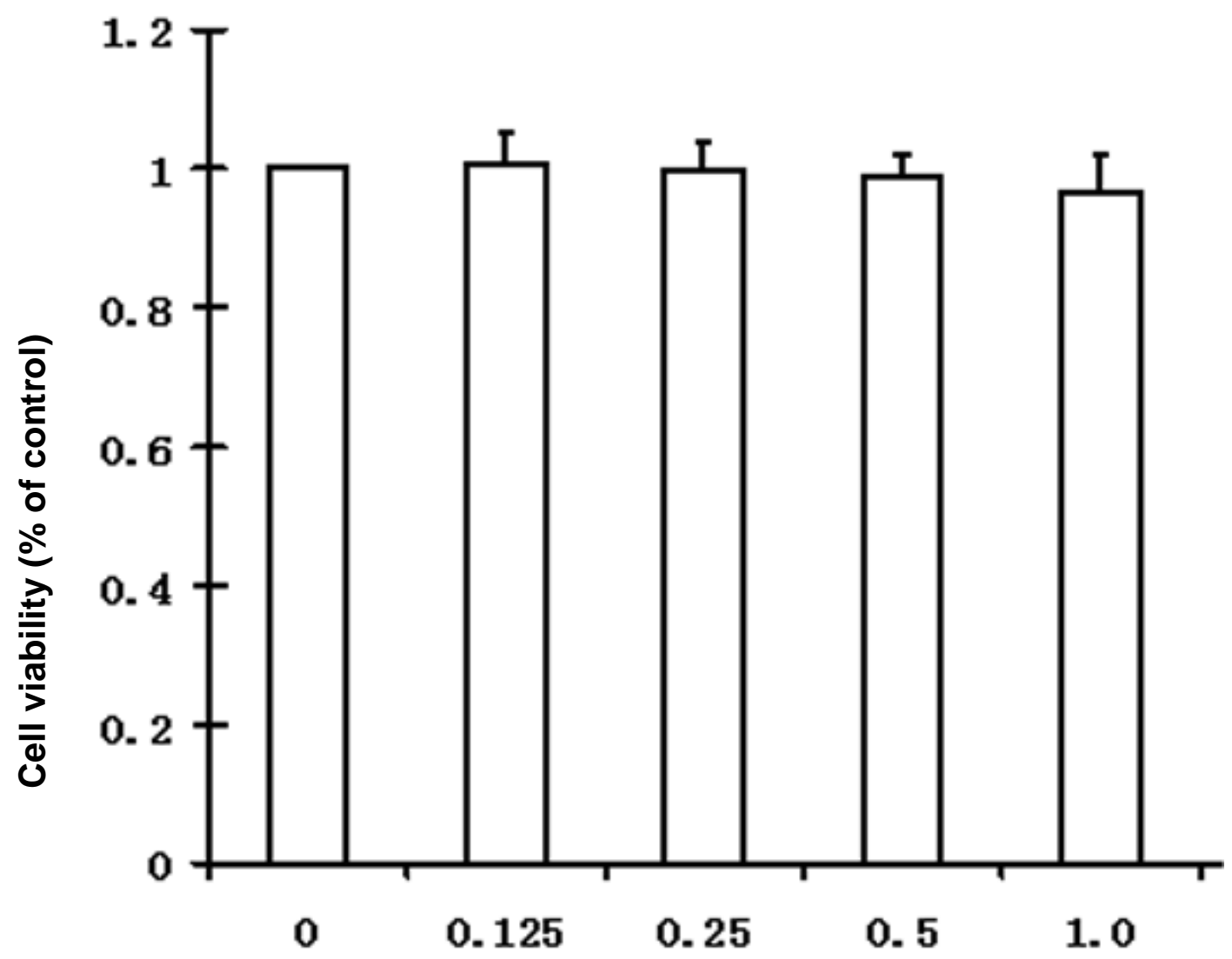

Oxymatrine $(\mathrm{mg} / \mathrm{mL}$

Figure 6. Figure 6. Effect of oxymatrine on the proliferation of lung fibroblasts. MTT assay was used to measure cell proliferation after fibroblasts were treated with different concentrations of OM for $48 \mathrm{~h}$. Percentage of cell proliferation was calculated as (OD of treated sample/OD of untreated control) $\times 100$. Data are mean \pm S.E.M.

indicated that EIF3 are involved in cell cycle, tumorigenesis and DNA repair. In humans, over-expression of EIF3 has been found in prostate, breast, and liver cancer. At the cellular level, EIF3 over-expression increases proliferation, growth and survival (Cappuzzo et al., 2009; Wang et al., 2008).

In this study, EIF3 was significantly down-regulated by $\mathrm{OM}$, which indicates the important roles of this protein in mediating the inhibiting effects of $\mathrm{OM}$ on fibroblasts. In the present study, using proteomic approach, we identified 5 protein spots that have altered expression in fibroblasts exposed to OM, compared with the control cells. The changed proteins were MRLC1, HSP27, PEPCK, TFSII and EIF3. Among them, the reduction of HSP27 induced by OM has been confirmed by RT-PCR and western-blot analysis at mRNA and protein levels. Moreover, since HSP27 is a cytoskeleton regulatory protein, the inhibitory effect of OM on motility of fibroblast was proven in the experiment. To verify the role of HSP27 and other changed proteins in mediating effects of OM on lung fibroblasts, further research needs to be carried out.

\section{ACKNOWLEDGMENTS}

This study was supported by National Natural Science Foundation of China (No 81072685), Scientific and Technical Research Project of Chongqing (CSTC, 2010AC5021) and Open Project of National Key Laboratory of Respiratory Diseases of China (NO.2007DA780154F0912).

\section{REFERENCES}

Cappuzzo F, Varella-Garcia M, Rossi E, Gajapathy S, Valente M, Drabkin H, Gemmill R (2009). MYC and EIF3H Coamplification significantly improve response and survival of non-small cell lung cancer patients (NSCLC) treated with gefitinib. J. Thorac. Oncol. 4:472-478. 
Chilosi M, Zamo A, Doglioni C, Reghellin D, Lestani M, Montagna L, Pedron S, Ennas MG, Cancellieri A, Murer B, Poletti V (2006). Migratory marker expression in fibroblast foci of idiopathic pulmonary fibrosis. Respir. Res. 7:95.

Datta A, Scotton CJ, Chambers RC (2011). Novel therapeutic approaches for pulmonary fibrosis. Br. J. Pharmacol. 163(1):141-72.

D'Hertog W, Overbergh L, Lage K, Ferreira GB, Maris M, Gysemans C, Flamez D, Cardozo AK, Van den Bergh G, Schoofs L, Arckens L, Moreau Y, Hansen DA, Eizirik DL, Waelkens E, Mathieu C (2007). Proteomics analysis of cytokine-induced dysfunction and death in insulin-producing INS-1E cells: new insights into the pathways involved. Mol. Cell Proteomics 6:2180-2199.

Dong Y, Xi H, Yu Y, Wang Q, Jiang K, Li L (2002). Effects of oxymatrine on the serum levels of $T$ helper cell 1 and 2 cytokines and the expression of the $S$ gene in hepatitis $B$ virus $S$ gene transgenic mice: a study on the anti-hepatitis B virus mechanism of oxymatrine. J. Gastroenterol. Hepatol. 17:1299-1306.

Elrick MM, Walgren JL, Mitchell MD, Thompson DC (2006). Proteomics: recent applications and new technologies. Basic Clin. Pharmacol. Toxicol. 98:432-441.

Gross TJ, Hunninghake GW (2001). Idiopathic pulmonary fibrosis. N. Engl. J. Med. 345:517-525.

Hiragami $\mathrm{F}$, Motoda $\mathrm{H}$, Takezawa $\mathrm{T}$, Takabayashi $\mathrm{C}$, Inoue $\mathrm{S}$, Wakatake Y, Kano Y (2009). Heat shock-induced three-dimensionallike proliferation of normal human fibroblasts mediated by pressed silk. Int. J. Mol. Sci. 10:4963-4976.

Huang J, Tang X, Ruan J, Ma H, Zou S (2010). Use of comparative proteomics to identify key proteins related to hepatic lipid metabolism in broiler chickens: evidence accounting for differential fat deposition between strains. Lipids 45:81-89.

Hubbard K, Catalano J, Puri RK, Gnatt A (2008). Knockdown of TFIIS by RNA silencing inhibits cancer cell proliferation and induces apoptosis. BMC Cancer 8:133.

Liu J, Liu Y, Klaassen CD (1994). The effect of Chinese hepatoprotective medicines on experimental liver injury in mice. J. Ethnopharmacol. 42:183-191.

Liu J, Manheimer E, Tsutani K, Gluud C (2003). Medicinal herbs for hepatitis C virus infection: a Cochrane hepatobiliary systematic review of randomized trials. Am. J. Gastroenterol. 98:538-544.

Liu L, Lu W, Ma Z, Li Z (2012). Oxymatrine attenuates bleomycininduced pulmonary fibrosis in mice via the inhibition of inducible nitric oxide synthase expression and the TGF- $\beta / S$ mad signaling pathway. Int J Mol Med. 2012 May; 29(5):815-822.

Kanai A, Kuzuhara T, Sekimizu K, Natori S (1991). Heterogeneity and tissue-specific expression of eukaryotic transcription factor S-IIrelated protein mRNA. J. Biochem. 109:674-677.

Kim MH, Kim MO, Kim YH, Kim JS, Han HJ (2009). Linoleic acid induces mouse embryonic stem cell proliferation via Ca2+/PKC, PI3K/Akt, and MAPKs. Cell Physiol. Biochem. 23:53-64.
Phan SH, Varani J, Smith D (1985). Rat lung fibroblast collagen metabolism in bleomycin-induced pulmonary fibrosis. J. Clin. Invest. 76:241-247.

Qian M, Sleat DE, Zheng H, Moore D, Lobel P (2008). Proteomics analysis of serum from mutant mice reveals lysosomal proteins selectively transported by each of the two mannose 6-phosphate receptors. Mol. Cell Proteomics 7:58-70.

Ruiz-Romero C, Calamia V, Mateos J, Martínez-Gomariz M, Fernández $\mathrm{M}$, Blanco FJ(2009). Mitochondrial dysregulation of osteoarthritic human articular chondrocytes analyzed by proteomics: a decrease in mitochondrial superoxide dismutase points to a redox imbalance. Mol. Cell Proteomics 8:172-189.

Santos MF, McCormack SA, Guo Z, Okolicany J, Zheng Y, Johnson L.R, Tigyi G (1997). Rho proteins play a critical role in cell migration during the early phase of mucosal restitution. J. Clin. Invest. 100:216225.

Shen XC, Yang YP, Xiao TT, Peng J, Liu XD (2011). Protective effect of oxymatrine on myocardial fibrosis induced by acute myocardial infarction in rats involved in TGF- $\beta_{1}$-Smads signal pathway. J. Asian Nat. Prod. Res. 13(3):215-24.

Shi GF, Li Q (2005). Effects of oxymatrine on experimental hepatic fibrosis and its mechanism in vivo. World J. Gastroenterol. 14;11(2):268-271.

Swant JD, Rendon BE, Symons M, Mitchell RA (2005). Rho GTPasedependent signaling is required for macrophage migration inhibitory factor-mediated expression of cyclin D1. J. Biol. Chem. 280:2306623072.

Tsai MC, Shen LF, Kuo HS, Cheng H, Chak KF (2008). Involvement of acidic fibroblast growth factor in spinal cord injury repair processes revealed by a proteomics approach. Mol. Cell Proteomics 7:16681687.

Wang J, Chen L, Li D, Yin Y, Wang X, Li P, Dangott LJ, Hu W, Wu G (2008). Intrauterine growth restriction affects the proteomes of the small intestine, liver, and skeletal muscle in newborn pigs. J. Nutr. 138:60-66.

Wu XL, Hang TJ, Shen JP, Zhang YD (2006). Determination and pharmacokinetic study of oxymatrine and its metabolite matrine in human plasma by liquid chromatography tandem mass spectrometry. J. Pharm. Biomed. Anal. 41:918-924. 